\title{
Serum Infliximab Cutoff trough Level Values for Maintaining Hematological Remission in Pediatric Inflammatory Bowel Disease
}

\author{
So Yoon $\mathrm{Choi}^{1,2}$, Ben Kang ${ }^{1,3}$, and Yon Ho Choe ${ }^{1}$ \\ ${ }^{\prime}$ Department of Pediatrics, Samsung Medical Center, Sungkyunkwan University School of Medicine, Seoul, ${ }^{2}$ Department of Pediatrics, Haeundae \\ Paik Hospital, Inje University College of Medicine, Busan, and ${ }^{3}$ Department of Pediatrics, School of Medicine, Kyungpook National University, \\ Daegu, Korea
}

Background/Aims: Infliximab (IFX) often loses its therapeutic effect in initial responders with inflammatory bowel disease (IBD) over time. Low serum IFX trough levels (TLs) are linked to poor clinical response and outcomes. Maintenance of optimal therapeutic IFX concentrations is important for sustaining response and achieving good clinical outcomes. Measurement of serum IFX TLs is helpful for determining a further proper therapeutic plan. However, adequate therapeutic IFX TLs in pediatric IBD is uncertain. We aimed to identify the cutoff values for IFX TLs associated with laboratory response to IFX maintenance therapy. Methods: Patients with pediatric IBD who had received IFX infusions between December 2008 and March 2015 at Samsung Medical Center were retrospectively investigated. We analyzed 239 blood samples that were collected from 103 pediatric patients. We measured IFX TLs at induction (6 and 14 weeks) and during maintenance therapy (>22 weeks, 8 weeks interval) by fluid-phase radioimmunoassays. Results: A significant association was found between the erythrocyte sedimentation rate (ESR) and IFX TLs during maintenance (correlation coefficient, -0.11; $p=0.0005$ ). A cutoff value of $18 \mathrm{~mm} / \mathrm{hr}$ for ESR was used to define higher levels. Receiver operating characteristic analysis identified optimal cutoff values: IFX TL >1.58 $\mu \mathrm{g} / \mathrm{mL}$ (sensitivity $82 \%$ and specificity $73 \%$ ). Conclusions: Cutoff values are considered a prerequisite for further investigating the clinical usefulness of measurements of IFX in patients maintained with IFX treatment. (Gut Liver 2019;13:541-548 )

Key Words: Infliximab; Drug monitoring; Pediatric inflammatory bowel disease

\section{INTRODUCTION}

Inflammatory bowel disease (IBD) refers to a group of chronic inflammatory conditions that affect the large and small intestines and repeatedly improve and worsen over time. Ulcerative colitis and Crohn's disease are the major types of IBD. While the exact pathogenesis underlying IBD remains unclear, it is thought to be associated with genetic and immunological abnormalities, and environmental factors, for example, stress and medications.

Immunosuppressive agents, including 5-aminosalicylate, steroids, azathioprine, and 6-mercaptopurine, are commonly used to treat IBD. Recently, tumor necrosis factor (TNF) inhibitors, which inhibit the activities of TNFs and other biological agents, have been introduced for the treatment of IBD, and they have gained attention as a potentially effective approach to treatment and as a potential substitute for steroid therapy.

IBD that occurs among young children and teenagers accounts for $15 \%$ to $20 \%$ of all IBD cases, and the incidence of IBD has been rising gradually in Korea and in other countries. ${ }^{2}$ IBD progresses differently in children compared with adults, and it is generally thought that IBD progression is worse in young children compared with that in adults. ${ }^{3,4}$

The treatment of pediatric IBD requires consideration of the factors that are relevant to the growth period and puberty, for example, physical autonomy, physical appearance, and selfesteem, which differs from the factors to be considered when treating adult IBD. ${ }^{5}$

Treatment methods that minimize the use of steroids, which impede children's growth and reduce bone density, must be developed. Infliximab (IFX), which is a TNF inhibitor, is widely used to treat IBD of moderate-to-high severity, and its effectiveness and safety in pediatric patients have been verified. ${ }^{6,7}$ The

\footnotetext{
Correspondence to: Yon Ho Choe

Department of Pediatrics, Samsung Medical Center, Sungkyunkwan University School of Medicine, 81 Irwon-ro, Gangnam-gu, Seoul 06351, Korea

Tel: +82-2-3410-3527, Fax: +82-2-3410-0043, E-mail: yonho.choe@samsung.com

Received on March 15, 2018. Revised on November 2, 2018. Accepted on November 20, 2018. Published online April 17, 2019 pISSN 1976-2283 eISSN 2005-1212 https://doi.org/10.5009/gnl18129

@ This is an Open Access article distributed under the terms of the Creative Commons Attribution Non-Commercial License (http://creativecommons.org/licenses/by-nc/4.0) which permits unrestricted non-commercial use, distribution, and reproduction in any medium, provided the original work is properly cited.
} 
dose of IFX typically used during remission induction therapy is $5 \mathrm{mg} / \mathrm{kg}$. Following the intravenous administration of IFX on the $0,2 n d$, and 6 th weeks of treatment, maintenance therapy is performed at 8-week intervals. Recent treatment guidelines published by the European Crohn's and Colitis Organisation and the European Society for Pediatric Gastroenterology Hepatology and Nutrition recommend that patients with IBD who exhibit poor prognostic factors during health examinations, including delayed growth and the presence of deep ulcers or anal fistulae, should receive early treatment with IFX rather thansteroids. ${ }^{8}$ The findings from a study that was conducted on pediatric patients with Crohn's disease of moderate-to-high severity showed that compared with the patients who did not receive TNF inhibitors, the rate of remission was higher and the rate of relapse was lower among the patients who had been actively treated with TNF inhibitors from the time of their initial diagnoses. ${ }^{9}$

Undertaking therapeutic drug monitoring during the administration of TNF inhibitors enables clinicians to implement safer and more effective treatment for IBD that is tailored to an individual patient's needs. Therapeutic drug monitoring measures the concentrations of the drug in the serum, and this can be useful for determining new pharmacotherapy directions. ${ }^{10}$ To maintain the therapeutic effects of IFX, an adequate serum IFX trough level (TL) must be maintained. Many studies' findings have shown that maintaining an appropriate serum drug level is associated with good clinical responses and outcomes, and prognoses. $^{11}$

The appropriate serum IFX level varies from study to study. Furthermore, studies that have investigated appropriate serum IFX levels in children are sparse, and none of the studies that have addressed this knowledge gap have been undertaken in Korea. Determining appropriate serum IFX cutoff levels will be useful for treatment planning, and they can be used to predict treatment outcomes. The present study aimed to determine the cutoff values for the serum IFX TLs that might lead to appropriate hematological responses and the effective treatment of pediatric patients with IBD.

\section{MATERIALS AND METHODS}

\section{Study subjects}

This study was a retrospective analysis of the patients who were younger than 18 years and underwent IFX therapy for IBD at Samsung Medical Center between December 2008 and March 2015. Subjects who underwent remission induction therapy on the $0,2 \mathrm{nd}$, and 6 th weeks of treatment followed by maintenance therapy at 8-week intervals, during which the IFX dose was maintained at $5 \mathrm{mg} / \mathrm{kg}$, and remained in clinical remission, were included in the study. Clinical remission was defined as a Pediatric Ulcerative Colitis Activity Index (PUCAI) ${ }^{12}$ of less than 10 or a Pediatric Crohn's Disease Activity Index (PCDAI) ${ }^{13}$ of less than 10. Patients were excluded if the IFX dose was in- creased during maintenance therapy, the administration interval was shortened, or if they developed autoantibodies against IFX during treatment.

This study was approved by the Institutional Review Board of Samsung Medical Center (2016-11-045), and was conducted in accordance with the Helsinki Declaration. Written informed consents were obtained.

\section{Serum drug level measurements}

Blood samples were collected immediately before IFX administration on the 6th and 14th weeks of treatment, and at more than 22 weeks after the therapy was initiated. The samples were stored at $-20^{\circ} \mathrm{C}$. The serum IFX levels were measured in each sample using an enzyme-linked immunosorbent (ELISA) assay (Matriks Biotechnology Co., Ltd, Ankara, Turkey) at an optical density of $450 \mathrm{~nm}$

\section{Variables investigated}

We retrospectively reviewed the patients' medical records and investigated the patients' ages, the times from the initial diagnoses to the initiation of IFX treatment, the patients' medication histories, including the use of 5-aminosalicylic acid, steroids, and azathioprine, and the patients' blood test parameters, including the hematocrit (Hct), C-reactive protein (CRP), and albu$\min (\mathrm{Alb})$ levels, and the erythrocyte sedimentation rates (ESRs), at the time of the initial diagnoses.

\section{Statistical analyses}

We used the Spearman rank correlation coefficient to analyze the correlations between the serum IFX levels and each hematological parameter, namely, the ESR, and the CRP, Hct, and Alb levels. We used the minimum p-value approach that reviewed all of the possible cutoff values for the hematological parameters by performing Wilcoxon rank-sum tests and using a generalized estimating equation. The minimum $\mathrm{p}$-value approach requires the choice of a selection interval. The cut-point is varied systematically within the selection interval, a p-value is computed for each cut-point, and the cut-point with the smallest p-value is chosen eventually. ${ }^{14}$ Analysis using generalized estimating equation was applied to repeated measurements. Logarithmic transformation was used for ESR and CRP with skewed distribution. We plotted receiver operating characteristic curves about the reference points at which the differences between the serum IFX levels were the most significant. Then, we determined the cutoff values by finding the points at which the differences between the specificities and the sensitivities were the smallest. The level of statistical significance was set at $\mathrm{p}<0.05$. SAS software version 9.4 (SAS Institute Inc., Cary, NC, USA) was used to perform the statistical analyses. 


\section{RESULTS}

\section{Patients' baseline characteristics}

We analyzed 239 blood samples that were collected from 103 pediatric patients, comprising 36 females and 67 males. Of these patients, 82 had Crohn's disease and 21 had ulcerative colitis. The mean age of the patients at the time of diagnosis The mean age of the patients at the time of diagnosis was 14.5 years, and the mean age at which the patients started IFX treatment was

Table 1. Baseline Characteristics of Patients $(n=103)$

\begin{tabular}{|c|c|}
\hline Variable & Value \\
\hline Male sex & $67(65)$ \\
\hline Crohn's disease & $82(80)$ \\
\hline \multicolumn{2}{|l|}{ Location of disease } \\
\hline \multicolumn{2}{|l|}{ Lower GI location } \\
\hline L1 & $2(2)$ \\
\hline $\mathrm{L} 2$ & $4(5)$ \\
\hline L3 & $76(93)$ \\
\hline \multicolumn{2}{|l|}{ Upper GI location } \\
\hline No involvement & $38(46)$ \\
\hline L4a & 15 (19) \\
\hline $\mathrm{L} 4 \mathrm{~b}$ & $19(23)$ \\
\hline $\mathrm{L} 4 \mathrm{a}+\mathrm{b}$ & $10(12)$ \\
\hline Perianal fistulas & $10(12)$ \\
\hline Median PCDAI at IFX start & $32.5(17.5-55)$ \\
\hline Ulcerative colitis & $21(20)$ \\
\hline \multicolumn{2}{|l|}{ Location of disease } \\
\hline E3 & $8(38)$ \\
\hline E4 & $13(62)$ \\
\hline Median PUCAI at IFX start & $65(55-70)$ \\
\hline Age at diagnosis, yr & $14.5(10.0-17.4)$ \\
\hline Age at IFX, yr & $14(13.3-17.5)$ \\
\hline Duration from diagnosis to IFX infusion, mo & $3(0.5-48)$ \\
\hline Concomitant IMM at start IFX & $100(97)$ \\
\hline Concomitant Mesalazine at start IFX & $98(95)$ \\
\hline Corticosteroid use prior to IFX & $19(18)$ \\
\hline Hematocrit, \% & $34.5(28.3-44.3)$ \\
\hline Albumin, g/dL & $4.0(2.8-4.6)$ \\
\hline $\mathrm{ESR}, \mathrm{mm} / \mathrm{hr}$ & $50(6-106)$ \\
\hline CRP, mg/dL & $1.14(0.04-7.51)$ \\
\hline
\end{tabular}

Data are presented as number (\%) or median (range).

GI, gastrointestinal; L1, distal 1/3 ileum \pm limited cecal disease; L2, colonic disease; L3, ileocolonic disease; L4a, upper disease proximal to ligament of Treitz; L4b, upper disease distal to the ligament of Treitz and proximal to the distal $1 / 3$ ileum; L4a+b, upper disease involvement in both L4a and L4b; PCDAI, Pediatric Crohn's Disease Activity Index; IFX, infliximab; E3, extensive (hepatic flexure distally); E4, pancolitis (proximal to hepatic flexure); PUCAI, Pediatric Ulcerative Colitis Activity Index; IMM, immunomodulator; ESR, erythrocyte sedimentation rate; CRP, C-reactive protein.
14 years (Table 1$)$.

\section{Analysis of the correlations between the serum IFX levels and the hematological markers}

We investigated the correlations between the serum IFX levels and the ESRs, the CRP levels, and the Hct levels. If the correlation is established, it can be used as a hematological index. On the 6th week of treatment, the serum IFX level was negatively correlated with the CRP level, with a correlation coefficient of -0.38 ( $p=0.0439$ ) (Table 2, Fig. 1). On the 14th week of treatment, the serum IFX level was negatively correlated with the CRP level and the ESR, with correlation coefficients of -0.54 $(\mathrm{p}=0.0011)$ and $-0.39(\mathrm{p}=0.0238)$, respectively (Table 3, Figs 2 and 3). At more than 22 weeks after the initiation of treatment, the serum IFX level was negatively correlated with the ESR, with a $\beta$ coefficient of $-0.11(p=0.0005)$ (Table 4). Based on these results, we decided to use the ESRs and the CRP levels to determine the cutoff values for the serum IFX levels.

\section{Minimum p-value approach}

After reviewing all of the possible cutoff values for the ESRs and the CRP levels, we decided that an ESR of $18 \mathrm{~mm} / \mathrm{hr}$ and a CRP level of $0.1 \mathrm{mg} / \mathrm{dL}$, which had the lowest p-values, should be included in the criteria for hematological remission, and the cutoff values were reviewed (Tables 5 and 6).

Table 2. Analysis of Correlations between the Serum Infliximab Level and Hematological Markers in the 6th Week of Treatment

\begin{tabular}{lcc}
\hline Variable & Spearman correlation coefficient & $\mathrm{p}$-value \\
\hline ESR & -0.05 & 0.7866 \\
CRP & -0.38 & 0.0439 \\
Albumin & 0.20 & 0.3091 \\
Hematocrit & -0.03 & 0.8861 \\
\hline
\end{tabular}

ESR, erythrocyte sedimentation rate; CRP, C-reactive protein.

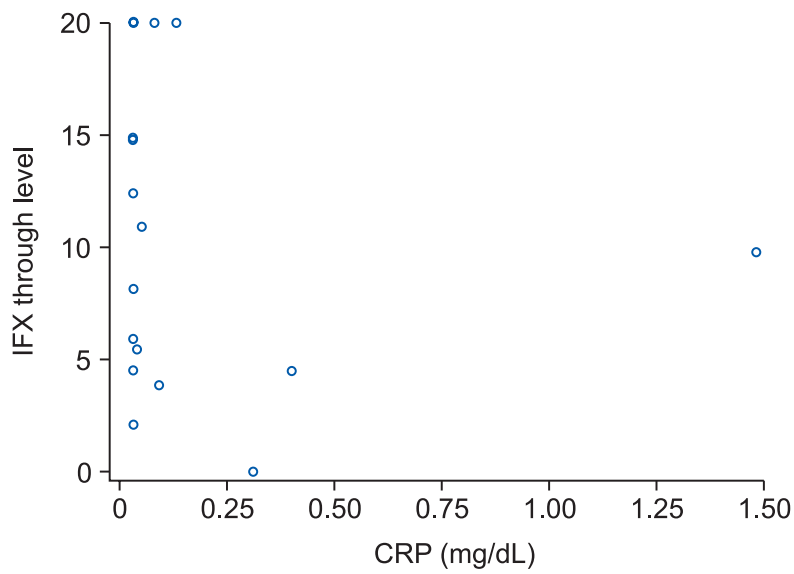

Fig. 1. The correlation between the infliximab (IFX) trough level and the C-reactive protein (CRP) level in the 6th week of treatment. 
Table 3. Analysis of Correlations between the Serum Infliximab Level and Hematological Markers on the 14th Week of Treatment

\begin{tabular}{lcc}
\hline Variable & Spearman correlation coefficient & $\mathrm{p}$-value \\
\hline ESR & -0.39 & 0.0238 \\
CRP & -0.54 & 0.0011 \\
Albumin & 0.20 & 0.2594 \\
Hematocrit & 0.02 & 0.8967 \\
\hline
\end{tabular}

ESR, erythrocyte sedimentation rate; CRP, C-reactive protein.

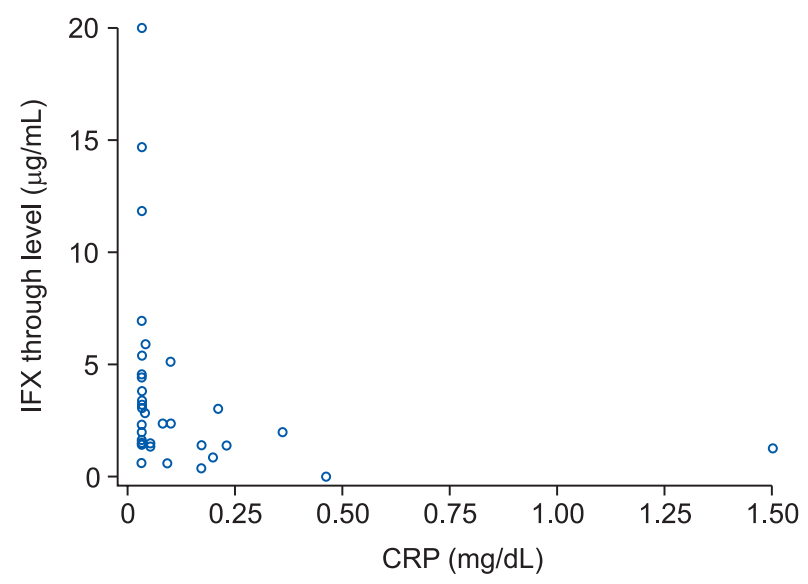

Fig. 2. The correlation between the infliximab (IFX) trough level and the C-reactive protein (CRP) level in the 6th week of treatment.

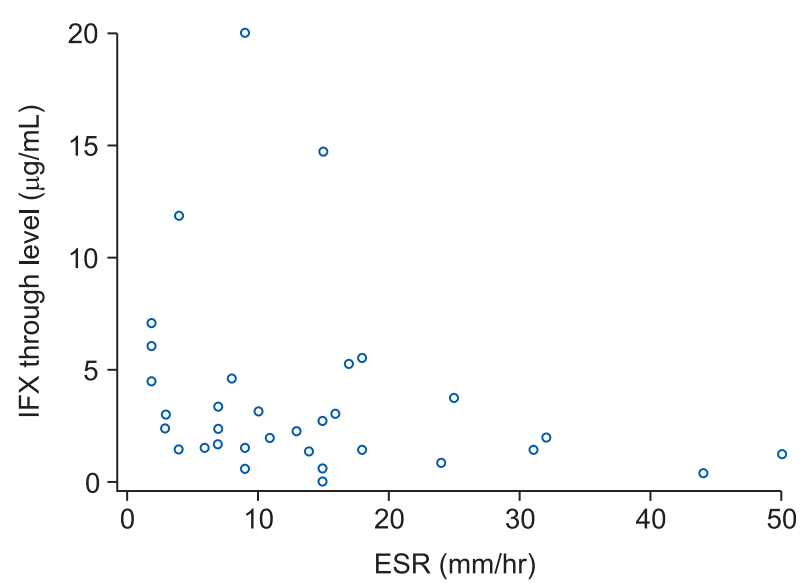

Fig. 3. The correlation between the infliximab (IFX) trough level and the erythrocyte sedimentation (ESR) rate in the 14th week of treatment.

\section{Cutoff values for the serum IFX levels}

Youden's index method ${ }^{15}$ was used to determine the sensitivities and the specificities of the best cutoff values for the serum IFX levels (Table 7). On the 6th week of treatment, a serum IFX level of $9.82 \mu \mathrm{g} / \mathrm{mL}$ (area under the curve [AUC], 0.65 [95\% confidence interval (CI), 0.34-0.95]; sensitivity, 60\%; specificity, $75 \%$ ) was required to maintain a CRP level at below $0.1 \mathrm{mg} /$ $\mathrm{dL}$. The patients were divided into two groups based on whether their ESR was greater than or less than $18 \mathrm{~mm} / \mathrm{hr}$, and since
Table 4. Analysis of Correlations between the Serum Infliximab Level and Hematological Markers after more than 22 Weeks of Maintenance Therapy

\begin{tabular}{lcc}
\hline \multicolumn{1}{c}{ Variable } & Spearman correlation coefficient & $\mathrm{p}$-value \\
\hline ESR & -0.11 & 0.0005 \\
CRP & -0.07 & 0.2542 \\
Albumin & 0.20 & 0.2264 \\
Hematocrit & -0.18 & 0.1815 \\
\hline
\end{tabular}

The generalized estimating equation was used to analyze repeated measurements. Logarithmic transformation was used for erythrocyte sedimentation rate (ESR) and C-reactive protein (CRP) values with skewed distributions.

Table 5. Cutoff Points of ESR

\begin{tabular}{lcc}
\hline Cutoff point $(\mathrm{mm} / \mathrm{hr})$ & p-value & -log 10 (p-value) \\
\hline ESR $<4$ vs $\geq 4$ & 0.0354 & 1.4510 \\
ESR $<5$ vs $\geq 5$ & 0.0670 & 1.1739 \\
ESR $<6$ vs $\geq 6$ & 0.1046 & 0.9805 \\
ESR $<7$ vs $\geq 7$ & 0.1234 & 0.9087 \\
ESR $<8$ vs $\geq 8$ & 0.1769 & 0.7523 \\
ESR $<9$ vs $\geq 9$ & 0.1711 & 0.7667 \\
ESR $<10$ vs $\geq 10$ & 0.1044 & 0.9813 \\
ESR $<11$ vs $\geq 11$ & 0.1109 & 0.9551 \\
ESR $<12$ vs $\geq 12$ & 0.1512 & 0.8204 \\
ESR $<13$ vs $\geq 13$ & 0.1396 & 0.8551 \\
ESR $<14$ vs $\geq 14$ & 0.0143 & 1.8447 \\
ESR $<15$ vs $\geq 15$ & 0.0009 & 3.0458 \\
ESR $<16$ vs $\geq 16$ & 0.0005 & 3.3010 \\
ESR $<17$ vs $\geq 17$ & 0.0006 & 3.2218 \\
ESR $<18$ vs $\geq 18$ & 0.0004 & 3.3979 \\
ESR $<19$ vs $\geq 19$ & 0.0005 & 3.3010 \\
ESR $<20$ vs $\geq 20$ & 0.0038 & 2.4202 \\
ESR $<21$ vs $\geq 21$ & 0.0074 & 2.1308 \\
ESR $<23$ vs $\geq 23$ & 0.0140 & 1.8539 \\
ESR $<27$ vs $\geq 27$ & 0.0060 & 2.2218 \\
ESR $<31$ vs $\geq 31$ & 0.0055 & 2.2596 \\
ESR $<34$ vs $\geq 34$ & 0.0097 & 2.0132 \\
ESR $<35$ vs $\geq 35$ & 0.0069 & 2.1612 \\
ESR $<44$ vs $\geq 44$ & 0.0261 & 1.5834 \\
ESR $<49$ vs $\geq 49$ & 0.0341 & 1.4672 \\
ESR $<51$ vs $\geq 51$ & 0.0055 & 2.2596 \\
ESR $<54$ vs $\geq 54$ & 0.0226 & 1.6459 \\
ESR $<57$ vs $\geq 57$ & 0.0647 & 1.1891 \\
ESR $<61$ vs $\geq 61$ & 0.0030 & 2.5229 \\
ESR $<82$ vs $\geq 82$ & 0.0025 & 2.6021 \\
\hline
\end{tabular}

The generalized estimating equation was used to analyze repeated measurements.

ESR, erythrocyte sedimentation rate. 
Table 6. Cutoff Points of CRP

\begin{tabular}{|c|c|c|}
\hline Cutoff point (mg/dL) & $\mathrm{p}$-value & -log10(p-value) \\
\hline $\mathrm{CRP}<0.03$ vs $\geq 0.03$ & 0.1237 & 0.9076 \\
\hline CRP $<0.033$ vs $\geq 0.033$ & 0.5745 & 0.2407 \\
\hline $\mathrm{CRP}<0.04$ vs $\geq 0.04$ & 0.5832 & 0.2342 \\
\hline $\mathrm{CRP}<0.05$ vs $\geq 0.05$ & 0.6010 & 0.2211 \\
\hline $\mathrm{CRP}<0.06 \mathrm{vs} \geq 0.06$ & 0.6218 & 0.2063 \\
\hline $\mathrm{CRP}<0.07 \mathrm{vs} \geq 0.07$ & 0.6435 & 0.1915 \\
\hline CRP $<0.08$ vs $\geq 0.08$ & 0.6908 & 0.1606 \\
\hline $\mathrm{CRP}<0.09$ vs $\geq 0.09$ & 0.7169 & 0.1445 \\
\hline $\mathrm{CRP}<0.1$ vs $\geq 0.1$ & 0.0125 & 1.9031 \\
\hline $\mathrm{CRP}<0.11$ vs $\geq 0.11$ & 0.0224 & 1.6498 \\
\hline $\mathrm{CRP}<0.13$ vs $\geq 0.13$ & 0.0266 & 1.5751 \\
\hline $\mathrm{CRP}<0.14 \mathrm{vs} \geq 0.14$ & 0.0470 & 1.3279 \\
\hline $\mathrm{CRP}<0.16$ vs $\geq 0.16$ & 0.0688 & 1.1624 \\
\hline CRP $<0.2$ vs $\geq 0.2$ & 0.0833 & 1.0794 \\
\hline $\mathrm{CRP}<0.22$ vs $\geq 0.22$ & 0.1011 & 0.9952 \\
\hline $\mathrm{CRP}<0.24$ vs $\geq 0.24$ & 0.1990 & 0.7011 \\
\hline $\mathrm{CRP}<0.37$ vs $\geq 0.37$ & 0.3365 & 0.4730 \\
\hline $\mathrm{CRP}<0.43$ vs $\geq 0.43$ & 0.3748 & 0.4262 \\
\hline $\mathrm{CRP}<0.59$ vs $\geq 0.59$ & 0.4318 & 0.3647 \\
\hline $\mathrm{CRP}<0.67$ vs $\geq 0.67$ & 0.5758 & 0.2397 \\
\hline $\mathrm{CRP}<0.74$ vs $\geq 0.74$ & 0.6724 & 0.1724 \\
\hline $\mathrm{CRP}<0.81$ vs $\geq 0.81$ & 0.7438 & 0.1285 \\
\hline $\mathrm{CRP}<0.85$ vs $\geq 0.85$ & 0.9459 & 0.0242 \\
\hline $\mathrm{CRP}<0.92$ vs $\geq 0.92$ & 0.8922 & 0.0495 \\
\hline $\mathrm{CRP}<1.28$ vs $\geq 1.28$ & 0.9548 & 0.0201 \\
\hline $\mathrm{CRP}<1.72$ vs $\geq 1.72$ & 0.1147 & 0.9404 \\
\hline
\end{tabular}

The generalized estimating equation was used to analyze repeated measurements.

CRP, C-reactive protein.

there was no significant difference between the two groups with respect to the serum IFX level, we could not calculate a cutoff value. On the 14th week of treatment, a serum IFX level of 1.42 $\mu \mathrm{g} / \mathrm{mL}$ (AUC, 0.85 [95\% CI, 0.70-0.99]; sensitivity, 75\%; specificity, 88\%) was required to maintain a CRP level at below 0.1 $\mathrm{mg} / \mathrm{dL}$, and a serum IFX level of $1.98 \mu \mathrm{g} / \mathrm{mL}$ (AUC, 0.76 [95\% CI, 0.54-0.97]; sensitivity, 83\%; specificity, 67\%) was required to maintain an ESR at below $18 \mathrm{~mm} / \mathrm{hr}$. After more than 22 weeks of maintenance therapy, a serum IFX level of $1.5 \mu \mathrm{g} / \mathrm{mL}$ (AUC, 0.79 [95\% CI, 0.67-0.91]; sensitivity, 75\%; specificity, 79\%) was required to maintain a CRP level at below $0.1 \mathrm{mg} / \mathrm{dL}$, and a serum IFX level of $1.58 \mu \mathrm{g} / \mathrm{mL}$ (AUC, 0.79 [95\% CI, 0.68-0.90]; sensitivity, 82\%; specificity, 73\%) was required to maintain an ESR at below $18 \mathrm{~mm} / \mathrm{hr}$.

In addition, cutoff values of IFX TL were obtained based on CRP below $0.5 \mathrm{mg} / \mathrm{dL}$, which is commonly used as a definition of hematologic remission. On the 6th week of treatment, a
Table 7. Cutoff Values

\begin{tabular}{ccc}
\hline Week & ESR \& CRP & Cutoff value \\
\hline 6 & ESR $<18 \mathrm{~mm} / \mathrm{hr}$ & NA \\
& $\mathrm{CRP}<0.5 \mathrm{mg} / \mathrm{dL}$ & 9.82 \\
& $\mathrm{CRP}<0.1 \mathrm{mg} / \mathrm{dL}$ & 9.82 \\
\multirow{2}{*}{14} & $\mathrm{ESR}<18 \mathrm{~mm} / \mathrm{hr}$ & 1.98 \\
& $\mathrm{CRP}<0.5 \mathrm{mg} / \mathrm{dL}$ & 1.28 \\
& $\mathrm{CRP}<0.1 \mathrm{mg} / \mathrm{dL}$ & 1.42 \\
\multirow{2}{*}{22} & $\mathrm{ESR}<18 \mathrm{~mm} / \mathrm{hr}$ & 1.58 \\
& $\mathrm{CRP}<0.5 \mathrm{mg} / \mathrm{dL}$ & $\mathrm{NA}$ \\
& $\mathrm{CRP}<0.1 \mathrm{mg} / \mathrm{dL}$ & 1.5 \\
\hline
\end{tabular}

ESR, erythrocyte sedimentation rate; CRP, C-reactive protein; NA, not available.

serum IFX level of $9.82 \mu \mathrm{g} / \mathrm{mL}$ (AUC, 0.88 [95\% CI, 0.68-1.0]; sensitivity, 100\%; specificity, 69\%) was required to maintain a CRP level at below $0.5 \mathrm{mg} / \mathrm{dL}$. On the 14 th week of treatment, a serum IFX level of $1.28 \mu \mathrm{g} / \mathrm{mL}$ (AUC, 0.86 [95\% CI, 0.72-0.99]; sensitivity, 100\%; specificity, 79.4\%) was required to maintain a CRP level at below $0.5 \mathrm{mg} / \mathrm{dL}$. After more than 22 weeks of maintenance therapy, the patients were divided into two groups based on whether their CRP was greater than or less than 0.5 $\mathrm{mg} / \mathrm{dL}$, and since there was no significant difference between the two groups with respect to the serum IFX level, we could not calculate a cutoff value.

\section{DISCUSSION}

Although the exact causes of and the risk factors associated with IBD remain unclear, it is believed that inflammatory cytokines play important roles in the development of IBD. ${ }^{16,17}$ TNF- $\alpha$, an inflammatory cytokine, induces the expression of adhesive proteins by vascular endothelial cells and it mobilizes white blood cells, which move into the mucous membranes, thereby increasing inflammation. Furthermore, TNF- $\alpha$ acts on connective tissues and fibroblasts to increase the production of matrix metalloproteinases, which cause tissue damage and increase the permeability of the intestine, thereby triggering symptoms that include diarrhea. ${ }^{18,19}$

To inhibit TNF- $\alpha$ activity, IFX, which is a monoclonal antibody with a high specificity and affinity for TNF- $\alpha$, was developed. Findings from studies have shown that IFX is effective at treating pediatric patients with moderate-to-severe IBD who do not respond to previously administered treatments, and that it heals the mucous membranes. ${ }^{20,21}$ IFX is widely used and its efficacy has been verified. However, while 70\% to 90\% of patients showed excellent responses soon after IFX treatment, their early remission rates were low at $20 \%$ to $50 \%$ following induction therapy, ${ }^{22}$ and the therapeutic effects of IFX disappeared over time in some patients, which occurred because an individual's 
response to treatment varies according to the biological mechanism underlying the disease and because of variations in the drug's pharmacodynamics.

IFX induces immune reactions, which may cause the formation of antibodies to IFX ${ }^{23,24}$ that reduce the half-life of IFX by increasing its turnover, thereby reducing the serum IFX levels and its therapeutic effects. ${ }^{25}$ Therefore, an adequate serum IFX level must be maintained, and clinical measurements of the serum levels of IFX and antibodies to IFX should be performed to determine future treatment plans and to enable clinicians to predict individual patient's treatment outcomes and to treat patients with appropriate doses of medication. ${ }^{26}$ However, the clinical application of serum drug level measurements is currently limited, because standardized guidelines have not been established that clarify the appropriate measurement interval and analytical methods.

Serum IFX levels can be affected by the dose administered and the treatment interval. The half-life of IFX is 7 to 12 days, and its maintenance spans 12 to 17 days when it is administered at $5 \mathrm{mg} / \mathrm{kg}$. Although the metabolic and elimination pathways of IFX have not been clearly identified, its turnover rate is very low at $11-15 \mathrm{~mL} / \mathrm{hr}^{27}$ The findings from a pharmacodynamics study showed that IFX accumulated when it was administered three times at $5 \mathrm{mg} / \mathrm{kg}$ on the $0,2 \mathrm{nd}$, and 6th weeks of treatment. The maximum concentration is usually reached 2 weeks after its administration, and the therapeutic concentration is maintained for 20 weeks after the initial administration. ${ }^{22}$ The simultaneous administration of immunosuppressive agents, including azathioprine and 6-mercaptopurine, can delay the decline in the serum IFX level and reduce the rate of autoantibody formation against IFX. ${ }^{28,29}$ In the present study, 100 out of 103 patients (97\%) used azathioprine in conjunction with IFX, and we believe that the differences in the serum drug levels that arose among the patients as a result of using immunosuppressive agents were miniscule. A study that compared pediatric and adult patients with Crohn's disease reported that the pharmacodynamics of IFX were affected by the patient's body weight, but not by the patient's age. ${ }^{30}$

The present study aimed to determine the cutoff values for the serum trough IFX levels that would maintain clinical remission and low ESRs and CRP levels, which are hematological markers of acute and chronic inflammation. Although it is desirable to confirm IFX TL to achieve mucosal healing, it is difficult to perform an endoscopy every time for pediatric patients. Therefore, we checked the IFX TL for hematologic remission using hematologic indexes that were routinely performed. The findings from a previous study showed that a lower serum Alb level, which is a hematological marker of the nutritional state, was associated with a higher IFX turnover rate. ${ }^{31}$ However, no association was found between Alb level and the serum IFX level in this study, and Alb was not included as one of the candidate hematological parameters. Ohem et al. ${ }^{32}$ showed that higher CRP and ESR levels were found in pediatric patients with lower IFX TLs. They determined the CRP level $<0.5 \mathrm{mg} / \mathrm{dL}$ as a marker of laboratory remission. In our study, The serum IFX level was significantly negatively correlated with the early CRP level and the ESR, and these hematological parameters were used to determine cutoff values for the serum IFX levels.

The findings from recent studies of adults have shown that a serum IFX level of $3 \mu \mathrm{g} / \mathrm{mL}$ or higher is required to maintain clinical remission during maintenance therapy. ${ }^{33,34}$ Median serum IFX levels of $17.6 \mu \mathrm{g} / \mathrm{mL}$ during interventional treatment and $3.55 \mu \mathrm{g} / \mathrm{mL}$ during maintenance therapy were determined from a study of pediatric patients. ${ }^{35}$ In a model that used CRP level $<0.5 \mathrm{mg} / \mathrm{dL}$ as the definition of laboratory remission, the optimal IFX TL was $3.5 \mu \mathrm{g} / \mathrm{mL} .^{32}$ In this study, serum IFX level of $9.82 \mu \mathrm{g} / \mathrm{mL}$ was required to maintain a CRP level at below $0.5 \mathrm{mg} / \mathrm{dL}$ in induction therapy. It was the same value as that for maintaining a CRP level at below $0.1 \mathrm{mg} / \mathrm{dL}$. These cutoff values may be higher than the actual values, because serum IFX concentrations from the 2nd and 6th weeks of the induction therapy were included in the determination of these cutoff values. In addition, these cutoff values were higher than those determined in our study. This may have been caused by the nonuniform administration intervals during maintenance therapy in the previously published study, ${ }^{33}$ which had a median administration interval of 6.6 weeks, whereas IFX was administered regularly at 8-week intervals in our study. On the other hand, the findings from another study demonstrated a serum IFX level of greater than $5.5 \mu \mathrm{g} / \mathrm{mL}$ during the 14th week of treatment, which is a prognostic factor for clinical remission. ${ }^{36}$ A variety of other serum IFX levels have also been reported from other studies. $^{37,38}$

The cutoff values for the serum IFX concentrations determined in this study were lower than those reported from previous studies. A serum IFX level that corresponds to a clinical response has not been identified, and the cutoff value can change according to the treatment objective and standard. The measurement of serum IFX levels may also vary depending on the ELISA kit used. One ELISA kit must be used to measure all of the serum IFX levels, and appropriate cutoff values must be determined based on the measurements to be used in clinical settings. It must also be noted that the use of other medications and their doses can affect the serum IFX levels. Optimizing the administration of IFX and using IFX efficiently can be achieved by maintaining the uniformity and consistency of the methods used to assess patients' responses to IFX treatment.

The limitation of this study was that we did not measure the fecal calprotectin levels. The fecal calprotectin levels correlated strongly with the endoscopic mucosal inflammations, and that these correlations were closer than indices such as the PUCAI, PCDAI, CRP levels and ESR. ${ }^{39}$ In the future, it is necessary to evaluate the cutoff value of IFX TL based on fecal calprotectin values in pediatric patients. 
In conclusion, by establishing cutoff values for the serum IFX levels, appropriate doses and administration intervals can be determined for individual patients on maintenance therapy, which will enable clinicians to plan treatment regimens and predict treatment outcomes. However, additional research is needed to determine the associations between the cutoff values and satisfactory treatment outcomes before they can be applied clinically.

\section{CONFLICTS OF INTEREST}

No potential conflict of interest relevant to this article was reported.

\section{AUTHOR CONTRIBUTIONS}

Study concept and design, data acquisition, drafting of the manuscript: S.Y.C. Data analysis and interpretation, critical revision of the manuscript for important intellectual content, statistical analysis: S.Y.C., B.K. Administrative, technical, or material support; study supervision: Y.H.C.

\section{ORCID}

Yon Ho Choe

https://orcid.org/0000-0003-1525-7688

\section{REFERENCES}

1. Xavier RJ, Podolsky DK. Unravelling the pathogenesis of inflammatory bowel disease. Nature 2007;448:427-434.

2. Kim SC, Ferry GD. Inflammatory bowel diseases in pediatric and adolescent patients: clinical, therapeutic, and psychosocial considerations. Gastroenterology 2004;126:1550-1560.

3. Seo JK. Pediatric Inflammatory Bowel Disease (IBD): phenotypic, genetic and therapeutic differences between early-onset and adultonset IBD. Korean J Pediatr Gastroenterol Nutr 2011;14:1-25.

4. Langholz E, Munkholm P, Krasilnikoff PA, Binder V. Inflammatory bowel diseases with onset in childhood: clinical features, morbidity, and mortality in a regional cohort. Scand J Gastroenterol 1997;32:139-147.

5. Guariso G, Gasparetto M, Visonà Dalla Pozza L, et al. Inflammatory bowel disease developing in paediatric and adult age. J Pediatr Gastroenterol Nutr 2010;51:698-707.

6. Kelsen JR, Grossman AB, Pauly-Hubbard H, Gupta K, Baldassano RN, Mamula P. Infliximab therapy in pediatric patients 7 years of age and younger. J Pediatr Gastroenterol Nutr 2014;59:758-762.

7. Rutgeerts P, D'Haens G, Targan S, et al. Efficacy and safety of retreatment with anti-tumor necrosis factor antibody (infliximab) to maintain remission in Crohn's disease. Gastroenterology 1999;117:761-769.

8. Ruemmele FM, Veres G, Kolho KL, et al. Consensus guidelines of ECCO/ESPGHAN on the medical management of pediatric Crohn's disease. J Crohns Colitis 2014;8:1179-1207.

9. Lee YM, Kang B, Lee Y, Kim MJ, Choe YH. Infliximab "top-down" strategy is superior to "step-up" in maintaining long-term remission in the treatment of pediatric Crohn disease. J Pediatr Gastroenterol Nutr 2015;60:737-743.

10. Steenholdt C, Brynskov J, Thomsen 0Ø, et al. Individualised therapy is more cost-effective than dose intensification in patients with Crohn's disease who lose response to anti-TNF treatment: a randomised, controlled trial. Gut 2014;63:919-927.

11. Maser EA, Villela R, Silverberg MS, Greenberg GR. Association of trough serum infliximab to clinical outcome after scheduled maintenance treatment for Crohn's disease. Clin Gastroenterol Hepatol 2006;4:1248-1254.

12. Turner D, Travis SP, Griffiths AM, et al. Consensus for managing acute severe ulcerative colitis in children: a systematic review and joint statement from ECCO, ESPGHAN, and the Porto IBD Working Group of ESPGHAN. Am J Gastroenterol 2011;106:574-588.

13. Hyams JS, Ferry GD, Mandel FS, et al. Development and validation of a pediatric Crohn's disease activity index. J Pediatr Gastroenterol Nutr 1991;12:439-447.

14. Mazumdar M, Glassman JR. Categorizing a prognostic variable: review of methods, code for easy implementation and applications to decision-making about cancer treatments. Stat Med 2000;19:113-132.

15. Youden WJ. Index for rating diagnostic tests. Cancer 1950;3:3235.

16. Fiocchi C. Inflammatory bowel disease: etiology and pathogenesis. Gastroenterology 1998;115:182-205.

17. Papadakis KA, Targan SR. Role of cytokines in the pathogenesis of inflammatory bowel disease. Annu Rev Med 2000;51:289-298.

18. Papadakis KA, Targan SR. Tumor necrosis factor: biology and therapeutic inhibitors. Gastroenterology 2000;119:1148-1157.

19. Van Deventer SJ. Tumour necrosis factor and Crohn's disease. Gut 1997;40:443-448.

20. Hyams J, Crandall W, Kugathasan S, et al. Induction and maintenance infliximab therapy for the treatment of moderate-to-severe Crohn's disease in children. Gastroenterology 2007;132:863-873.

21. Hyams JS, Lerer T, Griffiths A, et al. Long-term outcome of maintenance infliximab therapy in children with Crohn's disease. Inflamm Bowel Dis 2009;15:816-822.

22. Vande Casteele N, Gils A. Pharmacokinetics of anti-TNF monoclonal antibodies in inflammatory bowel disease: adding value to current practice. J Clin Pharmacol 2015;55 Suppl 3:S39-S50.

23. Ainsworth MA, Bendtzen K, Brynskov J. Tumor necrosis factor-alpha binding capacity and anti-infliximab antibodies measured by fluid-phase radioimmunoassays as predictors of clinical efficacy of infliximab in Crohn's disease. Am J Gastroenterol 2008;103:944948.

24. Vande Casteele N, Gils A, Singh S, et al. Antibody response to infliximab and its impact on pharmacokinetics can be transient. Am J Gastroenterol 2013;108:962-971.

25. Seow CH, Newman A, Irwin SP, Steinhart AH, Silverberg MS, 
Greenberg GR. Trough serum infliximab: a predictive factor of clinical outcome for infliximab treatment in acute ulcerative colitis. Gut 2010;59:49-54.

26. Afif W, Loftus EV Jr, Faubion WA, et al. Clinical utility of measuring infliximab and human anti-chimeric antibody concentrations in patients with inflammatory bowel disease. Am J Gastroenterol 2010;105:1133-1139.

27. Klotz U, Teml A, Schwab M. Clinical pharmacokinetics and use of infliximab. Clin Pharmacokinet 2007;46:645-660.

28. Love BL, Smith LS, Sarbah SA, Fowler FC. Azathioprine and infliximab: monotherapy or combination therapy in the treatment of Crohn's disease. Clin Med Insights Gastroenterol 2011;4:21-30.

29. Panaccione R, Ghosh S, Middleton S, et al. Combination therapy with infliximab and azathioprine is superior to monotherapy with either agent in ulcerative colitis. Gastroenterology 2014;146:392400.

30. Fasanmade AA, Adedokun OJ, Blank M, Zhou H, Davis HM. Pharmacokinetic properties of infliximab in children and adults with Crohn's disease: a retrospective analysis of data from 2 phase III clinical trials. Clin Ther 2011;33:946-964.

31. Fasanmade AA, Adedokun OJ, Olson A, Strauss R, Davis HM. Serum albumin concentration: a predictive factor of infliximab pharmacokinetics and clinical response in patients with ulcerative colitis. Int J Clin Pharmacol Ther 2010;48:297-308.

32. Ohem J, Hradsky 0, Zarubova K, et al. Evaluation of infliximab therapy in children with Crohn's disease using trough levels pre- dictors. Dig Dis 2018;36:40-48.

33. Feagan BG, Singh S, Lockton S, et al. 565 Novel infliximab (IFX) and antibody-to-infliximab (ATI) assays are predictive of disease activity in patients with Crohn's disease (CD). Gastroenterology 2012;142(5 Suppl 1):S-114.

34. Vaughn BP, Martínez-Vazquez M, Patwardhan V, Moss AC, Sandborn WJ, Cheifetz AS. 209 Prospective therapeutic drug monitoring to optimizing infliximab (IFX) maintenance therapy in patients with inflammatory bowel disease (IBD). Gastroenterology 2014;146(5 Suppl 1):S-54.

35. Hämäläinen A, Sipponen T, Kolho KL. Serum infliximab concentrations in pediatric inflammatory bowel disease. Scand J Gastroenterol 2013;48:35-41.

36. Ben-Horin S, Kopylov U, Chowers Y. Optimizing anti-TNF treatments in inflammatory bowel disease. Autoimmun Rev 2014;13:24-30

37. Moss AC. Optimizing the use of biological therapy in patients with inflammatory bowel disease. Gastroenterol Rep (Oxf) 2015;3:6368.

38. Steenholdt C, Bendtzen K, Brynskov J, Thomsen 0Ø, Ainsworth MA. Cut-off levels and diagnostic accuracy of infliximab trough levels and anti-infliximab antibodies in Crohn's disease. Scand J Gastroenterol 2011;46:310-318.

39. Aomatsu T, Yoden A, Matsumoto K, et al. Fecal calprotectin is a useful marker for disease activity in pediatric patients with inflammatory bowel disease. Dig Dis Sci 2011;56:2372-2377. 